\title{
Polymorphisms of the fibrinogen-beta gene are related to 2-hour glucose level after oral glucose tolerance test in Hong Kong Chinese
}

\author{
Louisa Y.F. Wong ${ }^{\mathrm{a}}$, Kwok Leung Ong ${ }^{\mathrm{a}}$, Bernard M.Y. Cheung ${ }^{\mathrm{a}, *}$, Raymond Y.H. Leung ${ }^{\mathrm{a}}$, \\ Yu Bun Man ${ }^{\mathrm{b}}$ and Tai Hing Lam ${ }^{\mathrm{c}, 1}$ \\ ${ }^{a}$ Department of Medicine, University of Hong Kong, Hong Kong, China \\ ${ }^{\mathrm{b}}$ Department of Physiology, Chinese University of Hong Kong, Hong Kong, China \\ ${ }^{\mathrm{c}}$ Department of Community Medicine, University of Hong Kong, Hong Kong, China
}

\begin{abstract}
Fibrinogen, an acute phase protein, is an important inflammatory marker that is associated with cardiovascular diseases. We studied the association of three common human fibrinogen $\beta$ gene $(F G B)$ variants, $-455 \mathrm{G}>\mathrm{A},-249 \mathrm{C}>\mathrm{T}$, and $-148 \mathrm{C}>\mathrm{T}$ with glycemic parameters in 265 non-diabetic Hong Kong Chinese subjects. Both $F G B$ variants, $-455 \mathrm{G}>\mathrm{A}$ and $-148 \mathrm{C}>\mathrm{T}$ were in complete linkage disequilibrium and were associated with higher levels of plasma fibrinogen and 2-h glucose after a 75 -g oral glucose load $(p<0.01)$. Carriers of $F G B$ AC-haplotype, comprising the two nucleotide variants at positions -455 and -249 , had higher fibrinogen level $(2.64 \pm 0.65$ vs $2.42 \pm 0.52 \mathrm{~g} / \mathrm{L}, p=0.002)$ and 2-h glucose after a 75 -g oral glucose load $(5.87 \pm 1.14$ vs $5.47 \pm 1.22 \mathrm{~g} / \mathrm{L}, p=0.006)$. The associations were significant in men, but not women. In stepwise multiple regression analysis, AC-haplotype was independently associated with plasma fibrinogen level and 2-h glucose $(p=0.002$ and 0.010 respectively). This suggests that fibrinogen may play a role in the development of impaired glucose tolerance.
\end{abstract}

Keywords: Fibrinogen, haplotype, impaired glucose tolerance, polymorphism

\section{Introduction}

Fibrinogen is an acute phase protein, in which its hepatic synthesis is mediated by interleukin-6 (IL6) [5]. It is an important inflammatory marker that is associated with cardiovascular diseases [8]. Elevated fibrinogen level is associated with age, obesity, smoking, elevated low density lipoprotein cholesterol, elevated triglycerides, inflammation, diabetes mellitus, hypertension, and the metabolic syndrome $[8,9,11,23]$.

\footnotetext{
${ }^{*}$ Corresponding author: Prof. Bernard M.Y. Cheung, Department of Clinical Pharmacology, Division of Medical Sciences, University of Birmingham, United Kingdom. Tel.: +44 121 4146874; Fax: +44 121 4141355; E-mail: b.cheung@bham.ac.uk.

${ }^{1}$ Hong Kong Cardiovascular Risk Factor Prevalence Study Steering Committee.
}

\begin{abstract}
A higher fibrinogen level is associated with glucose intolerance and severity of diabetes [16,21]. We previously reported that the IL- 6 gene $-572 \mathrm{C}>\mathrm{G}$ polymorphism was associated with higher plasma fibrinogen level [28]. Fibrinogen consists of three polypeptides, $\alpha, \beta$, and $\gamma$, in which the encoding genes are clustered together on the chromosome 4q23-32 [13]. The synthesis of the $\beta$ chain is the rate-limiting step in the synthesis of fibrinogen [22]. Both $-455 \mathrm{G}>\mathrm{A}$ and $-148 \mathrm{C}>\mathrm{T}$ polymorphism in fibrinogen- $\beta$ gene $(F G B)$ have been shown to be associated with increased fibrinogen level [23,24]. A recent study also demonstrates significant association of $-455 \mathrm{G}>\mathrm{A}$ with increased fasting insulin level [18]. Therefore, we hypothesized that single nucleotide polymorphisms (SNPs) in $F G B$ may be associated with a higher risk for the metabolic syndrome, or at least its related glycemic component, like
\end{abstract}


insulin resistance, plasma glucose, and insulin level. We, therefore, studied three known SNPs in the promoter region of $F G B,-455 \mathrm{G}>\mathrm{A}(\mathrm{rs} 1800790),-249 \mathrm{C}>\mathrm{T}$ (rs1800788), and -148C $>$ T (rs1800787) with plasma glucose level among 265 non-diabetic subjects.

\section{Subjects and methods}

\subsection{Subjects}

265 unrelated non-diabetic Southern Chinese subjects of Han race living in Hong Kong were included in this study. The subjects were randomly selected from a previous cohort of subjects randomly recruited from the general population aged 25-74 years in 19951996 [12]. The study protocol has been approved by the Institutional Review Board, and written informed consent was obtained from all participants. All subjects were without diabetes, impaired fasting glucose, or impaired glucose tolerance according to the diagnostic criteria of the American Diabetes Association [1].

Physical examination (including measurement of height, weight, body mass index, waist circumference) and a full medical history (including past medical history, drug history, family history, smoking status) was obtained with a standard questionnaire. Subjects were defined as either current, former, or never smoker. Hypertension was defined as blood pressure $\geqslant 140 / 90 \mathrm{mmHg}$ or taking anti-hypertensive drug [6]. Blood pressure, triglyceride, low density lipoprotein (LDL) cholesterol, high density lipoprotein (HDL) cholesterol, 75-g oral glucose tolerance test (OGTT), fasting glucose, insulin, and homeostasis model assessment of insulin resistance index (HOMA-IR) were measured as described previously [16,28]. Fibrinogen (coefficient of variation $4.5 \%$ within run and $6.1 \%$ between runs) was measured in the Haematology Laboratory of the Department of Pathology, Queen Mary Hospital within 24 hours by the Clauss Method on the Cobas Fibro (Roche Diagnostics, Basle, Switzerland) $[15,16]$. Standardization was carried out using calibrated plasma for fibrinogen (Thrombosis Center, Whittington Hospital, Manchester, UK) which was calibrated against the First International Standard Plasma Fibrinogen (National Institute for Biological Standards and Control 89:644).

\subsection{Genotyping}

Blood sample was taken and genomic DNA was extracted from the buffy coat as described previously [20,
28]. Genotyping of the three known SNPs in positions, $-455,-249$, and -148 of $F G B$ were performed using the Sequenom MassARRAY system (Sequenom, San Diego CA) which utilizes Matrix Assisted Laser Desorption Ionization-Time Of Flight (MALDI-TOF) technology.

\subsection{Statistical analysis}

Statistical analysis was performed using SPSS 13.0. Genotype frequencies for each SNP were tested for Hardy-Weinberg equilibrium. Haploview (ver. 3.2) was used to assess linkage disequilibrium for all possible SNP pairs by determining $r^{2}$ [2]. Haplotypes were predicted using the programme PHASE (ver. 2.1.1) [25, 26]. For haplotype analysis, subjects who carried a particular haplotype with a probability $\geqslant 0.99$ were included. Correction for multiple testing was performed by Bonferroni's correction. Data were reported as mean \pm standard deviation (SD), but the median (inter-quartile range) of fasting insulin, HOMA-IR, and triglyceride were given because of their skewed distribution. Comparisons of clinical characteristics were performed using unpaired student's t test or Mann-Whitney U test where appropriate, and Fisher's exact test was performed for categorical variables. Correlations of fibrinogen with other variables were analyzed by using Pearson correlations. Stepwise multiple linear regression was used to assess the independent association of $F G B$ haplotype with plasma fibrinogen and 2-h postOGTT glucose. A 2-tailed $p$ value $<0.05$ was considered statistically significant.

\section{Results}

\subsection{Baseline characteristics}

The clinical characteristics of the 265 subjects are shown in Table 1 . In this study, all the subjects were not taking any cholesterol lowering medications and only 12 subjects were taking anti-hypertensive medications. Compared to women, men had significantly higher diastolic blood pressure, waist circumference, LDL cholesterol, triglyceride, fasting glucose, and percentage of smoking, but lower HDL cholesterol, 2$\mathrm{h}$ glucose, fasting insulin, HOMA-IR, and fibrinogen level. Among all these subjects, fibrinogen level was strongly correlated positively with age, body mass index, 2-h glucose, fasting insulin, and HOMA-IR, but not fasting glucose (Table 2). 
Table 1

Baseline clinical characteristics of 265 non-diabetic subjects

\begin{tabular}{lccr}
\hline & Men $(n=140)$ & Women $(n=125)$ & \multicolumn{1}{c}{$p$} \\
\hline Age (years) & $47.3 \pm 11.6$ & $45.9 \pm 10.9$ & 0.288 \\
Systolic blood pressure $(\mathrm{mmHg})$ & $120.0 \pm 14.6$ & $118.6 \pm 18.0$ & 0.467 \\
Diastolic blood pressure $(\mathrm{mmHg})$ & $76.1 \pm 9.1$ & $73.2 \pm 10.6$ & 0.016 \\
Hypertension $(\%)$ & 14.3 & 12.8 & 0.858 \\
Current smoker $(\%)$ & 39.3 & 4.0 & $<0.001$ \\
Body mass index $\left(\mathrm{kg} / \mathrm{m}^{2}\right)$ & $23.8 \pm 3.2$ & $24.0 \pm 3.6$ & 0.626 \\
Waist circumference $(\mathrm{cm})$ & $81.2 \pm 9.1$ & $74.9 \pm 8.0$ & $<0.001$ \\
LDL cholesterol $(\mathrm{mM})$ & $3.3 \pm 0.7$ & $3.0 \pm 0.7$ & 0.001 \\
HDL cholesterol $(\mathrm{mM})$ & $1.2 \pm 0.3$ & $1.4 \pm 0.3$ & $<0.001$ \\
Triglyceride $(\mathrm{mM})$ & $1.00(0.80-1.46)$ & $0.90(0.66-1.20)$ & 0.007 \\
Fasting glucose $(\mathrm{mM})$ & $5.13 \pm 0.42$ & $4.98 \pm 0.37$ & 0.002 \\
2-h glucose $(\mathrm{mM})$ & $5.35 \pm 1.30$ & $6.00 \pm 0.97$ & $<0.001$ \\
Fasting insulin $(\mathrm{mIU} / \mathrm{L})$ & $4.4(2.8-6.0)$ & $5.2(3.5-7.5)$ & 0.008 \\
HOMA-IR & $0.98(0.64-1.44)$ & $1.10(0.76-1.80)$ & 0.027 \\
Fibrinogen $(\mathrm{g} / \mathrm{L})$ & $2.42 \pm 0.54$ & $2.65 \pm 0.62$ & 0.001 \\
\hline
\end{tabular}

LDL, low density lipoprotein; HDL, high density lipoprotein; HOMA-IR, homeostasis model assessment of insulin resistance index.

Data are expressed as mean $\pm \mathrm{SD}$ or median (inter-quartile range) unless otherwise stated.

Table 2

Correlation of fibrinogen with age and glycemic parameters

\begin{tabular}{lcr}
\hline & \multicolumn{2}{c}{ Fibrinogen $(\mathrm{g} / \mathrm{L})$} \\
\cline { 2 - 3 } & \multicolumn{1}{c}{$r$} & \multicolumn{1}{c}{$p$} \\
\hline Age (years) & 0.300 & $<0.001$ \\
Body mass index $\left(\mathrm{kg} / \mathrm{m}^{2}\right)$ & 0.160 & 0.009 \\
Fasting glucose $(\mathrm{mM})$ & 0.030 & 0.623 \\
2-h glucose $(\mathrm{mM})$ & 0.197 & 0.001 \\
Fasting insulin $(\mathrm{mIU} / \mathrm{L})^{*}$ & 0.152 & 0.019 \\
HOMA-IR* & 0.150 & 0.020 \\
\hline HOMA-IR, homeostasis model assessment of in- \\
sulin resistance index; $r$, Pearson correlation co- \\
efficients. \\
* Data are logarithmically transformed.
\end{tabular}

\subsection{SNP Genotyping}

In $F G B,-455 \mathrm{G}>\mathrm{A}$ and $-148 \mathrm{C}>\mathrm{T}$ polymorphisms were in complete linkage disequilibrium $\left(r^{2}=1.0\right)$. Therefore, only the variant $-455 \mathrm{G}>\mathrm{A}$ was tested and reported in subsequent analysis. The minor $-249 \mathrm{~T}$ allele was not detected in any individual carrying the minor allele of $-455 \mathrm{G}>\mathrm{A}$ polymorphism. Table 3 shows the results of genotyping of these two SNPs in $F G B$ $(-455 \mathrm{G}>\mathrm{A}$ and $-249 \mathrm{C}>\mathrm{T})$. For each SNP, the observed genotype frequencies showed no significant deviation from Hardy-Weinberg equilibrium. Characteristics of subjects who were homozygous for the minor allele or heterozygous were combined together into the same group in all remaining analyses to increase the sample size for comparison.

\subsection{Association with plasma fibrinogen and $2-h$ glucose levels}

The $F G B$ variant, $-455 \mathrm{~A}$ was associated with higher plasma fibrinogen and 2-h glucose level, which remained significant after correction for multiple testing (Table 3). The most common two-locus haplotypes of $F G B$, comprising the two nucleotide variants at positions -455 and -249 were GT, AC, and GC. As expected, fibrinogen level and 2-h glucose level were significantly higher in AC-haplotype carriers than non-carriers, which remained significant after correction for multiple testing (Table 3). However, none of the single variants or haplotypes were associated with fasting glucose, fasting insulin, and HOMA-IR $(p>$ 0.05). There were no significant differences in baseline clinical characteristics between AC-haplotype carriers and non-carriers, except that AC-haplotype carriers had lower HDL cholesterol level than non-carriers (1.33 \pm 0.35 vs $1.24 \pm 0.32 \mathrm{mM}, p=0.031)$. The association of 2-h glucose level with AC-haplotype remained significant after adjusting for age, sex, body mass index, fasting glucose, fasting insulin, and HDL cholesterol ( $\beta=0.155, p=0.008)$. Further adjustment for fibrinogen level did not affect the association significantly $(\beta=0.155, p=0.009)$.

\subsection{Sex-specific analysis}

In sex-specific analysis (Table 4), the association of AC-haplotype with fibrinogen and 2-h glucose level was significant only in men, but not women. The AC-haplotype was associated with a higher fasting in- 
Table 3

Association of $F G B$ genotypes and haplotypes with plasma fibrinogen and 2-h glucose

\begin{tabular}{|c|c|c|c|c|c|c|}
\hline \multicolumn{2}{|c|}{ Genotypes / haplotypes* } & \multirow{3}{*}{$\begin{array}{l}\begin{array}{l}\text { No. }(\%) \text { of } \\
\text { genotypes }\end{array} \\
139(52.5)\end{array}$} & \multicolumn{2}{|c|}{ Fibrinogen } & \multicolumn{2}{|c|}{ 2-h glucose } \\
\hline & & & \multirow{2}{*}{$\frac{\mathrm{g} / \mathrm{L}}{2.42 \pm 0.52}$} & \multirow{2}{*}{$\begin{array}{c}p \\
0.002\end{array}$} & \multirow{3}{*}{$\begin{array}{c}\mathrm{mM} \\
5.47 \pm 1.22 \\
5.87 \pm 1.14\end{array}$} & \multirow{2}{*}{$\frac{p}{0.006}$} \\
\hline$-455(\mathrm{rs} 1800790)$ & GG & & & & & \\
\hline & GA & $106(40.0)$ & & & & \\
\hline & $\mathrm{AA}$ & $20(7.5)$ & & & & \\
\hline & $\mathrm{GA}+\mathrm{AA}$ & $126(47.5)$ & $2.64 \pm 0.65$ & & & \\
\hline \multirow[t]{4}{*}{$-249(\mathrm{rs} 1800788)$} & $\mathrm{CC}$ & $70(26.4)$ & $2.56 \pm 0.54$ & 0.624 & $5.65 \pm 1.27$ & 0.975 \\
\hline & $\mathrm{CT}$ & $122(46.0)$ & & & $5.66 \pm 1.17$ & \\
\hline & $\mathrm{TT}$ & $73(27.5)$ & & & & \\
\hline & $\mathrm{CT}+\mathrm{TT}$ & $195(73.6)$ & $2.52 \pm 0.62$ & & & \\
\hline \multirow[t]{4}{*}{ GT } & Non-carrier & $70(26.4)$ & $2.56 \pm 0.54$ & 0.624 & $5.65 \pm 1.27$ & 0.975 \\
\hline & Carrier (1 copy) & $122(46.0)$ & & & $5.66 \pm 1.17$ & \\
\hline & Carrier ( 2 copies) & $73(27.5)$ & & & & \\
\hline & Carrier ( 1 or 2 copies) & $195(73.6)$ & $2.52 \pm 0.61$ & & & \\
\hline \multirow[t]{4}{*}{$\mathrm{AC}$} & Non-carrier & $139(52.5)$ & $2.42 \pm 0.52$ & 0.002 & $5.47 \pm 1.22$ & 0.006 \\
\hline & Carrier (1 copy) & $106(40.0)$ & & & $5.87 \pm 1.14$ & \\
\hline & Carrier ( 2 copies) & $20(7.5)$ & & & & \\
\hline & Carrier ( 1 or 2 copies) & $126(47.5)$ & $2.64 \pm 0.65$ & & & \\
\hline \multirow[t]{4}{*}{ GC } & Non-carrier & $161(60.8)$ & $2.57 \pm 0.60$ & 0.120 & $5.76 \pm 1.15$ & 0.098 \\
\hline & Carrier ( 1 copy) & $92(34.7)$ & & & $5.51 \pm 1.26$ & \\
\hline & Carrier ( 2 copies) & $12(4.5)$ & & & & \\
\hline & Carrier ( 1 or 2 copies) & $104(39.2)$ & $2.46 \pm 0.59$ & & & \\
\hline
\end{tabular}

Plasma fibrinogen and 2-h glucose levels are expressed as mean \pm SD.

* The most common two-locus haplotypes, comprising the two nucleotide variants of $F G B$ at positions, -455 and -249 .

Table 4

Sex-specific association of $F G B$ AC-haplotypes with plasma fibrinogen and 2-h glucose

\begin{tabular}{|c|c|c|c|c|c|c|}
\hline \multirow[t]{2}{*}{ Genotypes / haplotypes* } & \multicolumn{3}{|c|}{$\operatorname{Men}(n=140)$} & \multicolumn{3}{|c|}{ Women $(n=125)$} \\
\hline & Non-carrier & Carrier ( 1 or 2 copies) & $p$ & Non-carrier & Carrier ( 1 or 2 copies) & $p$ \\
\hline $\mathrm{n}$ & 73 & 67 & & 66 & 59 & \\
\hline Fibrinogen $(\mathrm{g} / \mathrm{L})$ & $2.27 \pm 0.44$ & $2.57 \pm 0.61$ & 0.001 & $2.58 \pm 0.55$ & $2.73 \pm 0.69$ & 0.202 \\
\hline Fasting glucose (mM) & $5.10 \pm 0.46$ & $5.17 \pm 0.37$ & 0.353 & $5.03 \pm 0.36$ & $4.93 \pm 0.37$ & 0.337 \\
\hline 2 -h glucose $(\mathrm{mM})$ & $5.05 \pm 1.26$ & $5.67 \pm 1.28$ & 0.005 & $5.92 \pm 1.01$ & $6.09 \pm 0.92$ & 0.337 \\
\hline Fasting insulin (mIU/L) & $4.0(2.7-5.7)$ & $4.7(3.0-7.5)$ & 0.041 & $6.4(0.4-8.6)$ & $4.4(3.1-6.6)$ & 0.049 \\
\hline HOMA-IR & $0.86(0.56-1.32)$ & $1.12(0.69-1.84)$ & 0.040 & $1.44(0.83-1.94)$ & $0.98(0.67-1.41)$ & 0.045 \\
\hline
\end{tabular}

Data are expressed as mean \pm SD or median (inter-quartile range) unless otherwise stated.

sulin and HOMA-IR in men, but lower fasting insulin and HOMA-IR in women, although such association in men and women was not significant after correction for multiple testing.

\subsection{Multiple linear regression analysis}

As shown in Table 5, in a stepwise multiple linear regression analysis which includes the FGB AChaplotype and other potential confounding variables in the model, the AC-haplotype was an independent predictor of plasma fibrinogen and 2-h glucose levels.

\section{Discussion}

Fibrinogen has been recognized as an important inflammatory risk factor for cardiovascular events, and exerts significant effects on endothelial function and blood viscosity [14]. Higher level of fibrinogen indicates that hypofibrinolysis and increased vascular inflammation might be present in subjects with hypertension and the metabolic syndrome. As elevated fibrinogen level is associated with diabetes mellitus and the metabolic syndrome $[8,9,11,23]$, it would be expected that $F G B$ variants such as $-455 \mathrm{G}>\mathrm{A}$ and $-148 \mathrm{C}>\mathrm{T}$, which are associated with higher fibrinogen level, may also be associated with elevated glucose level among healthy non-diabetic subjects. To our knowledge, this is the first study investigating the association of the genetic polymorphisms in $F G B$ with 2-h glucose during OGTT. This suggests that SNPs in FGB may be associated with impaired glucose tolerance in non-diabetic Hong Kong Chinese. 
Table 5

Independent association of $F G B$ AC-haplotype with fibrinogen level and 2-h glucose: results of stepwise multiple regression analyses

\begin{tabular}{|c|c|c|c|c|}
\hline \multirow[t]{2}{*}{ Independent variables } & \multicolumn{2}{|c|}{ Fibrinogen $(\mathrm{g} / \mathrm{L})$} & \multicolumn{2}{|c|}{ 2-h glucose $(\mathrm{mM})$} \\
\hline & $\beta$ & $p$ & $\beta$ & $p$ \\
\hline ACT-haplotype (referent: non-carrier) & 0.176 & 0.002 & 0.151 & 0.010 \\
\hline Age (years) & 0.326 & $<0.001$ & - & - \\
\hline Body mass index $\left(\mathrm{kg} / \mathrm{m}^{2}\right)$ & - & - & 0.165 & 0.007 \\
\hline Sex (referent: male) & 0.295 & $<0.001$ & 0.355 & $<0.001$ \\
\hline Fasting glucose (mM) & - & - & 0.198 & 0.001 \\
\hline Fasting insulin (mIU/L) & 0.205 & 0.001 & - & - \\
\hline HDL cholesterol (mM) & - & - & -0.157 & 0.013 \\
\hline Smoking (referent: never smoker) & 0.176 & 0.011 & - & - \\
\hline
\end{tabular}

HDL, high density lipoprotein; $\beta$, standardized regression coefficient.

In the stepwise multiple regression analyses, independent variables in the model include age, sex, smoking (never, former and current smokers), body mass index, waist circumference, systolic blood pressure, diastolic blood pressure, low density lipoprotein cholesterol, high density lipoprotein cholesterol, triglyceride (logarithmically transformed), fasting glucose, 2-h glucose, fasting insulin (logarithmically transformed), homeostasis model assessment of insulin resistance index (logarithmically transformed), fibrinogen level, and the FGB AChaplotype. $R^{2}$ was 0.213 and 0.221 for fibrinogen level and 2 -h glucose respectively. "_" indicates those variables which were insignificant and excluded from the stepwise regression model.

In this study, carriers of the AC-haplotype had significantly higher fibrinogen and 2-h glucose level than those who did not carry the haplotype, especially among men. The associations were confirmed by multivariate regression analyses even after adjusting for other potential confounding factors. The $-455 \mathrm{G}>\mathrm{A}$ polymorphism in $F G B$ has been shown to be associated with increased fibrinogen level [23,24] and our study has confirmed such association in the Hong Kong Chinese population. In a study of healthy Caucasian adults, the $-455 \mathrm{G}>\mathrm{A}$ polymorphism was associated with higher fasting insulin level in men, but lower level in women [18]. Our study is the first report of similar findings in a different population, although the association with fasting insulin was not significant after correction for multiple testing. Moreover, we further reveal a much stronger association of $-455 \mathrm{G}>\mathrm{A}$ polymorphism with plasma 2-h glucose level. Such association is independent of fibrinogen level as adjustment for fibrinogen level did not reduce the association significantly. In fact, the $-455 \mathrm{G}>\mathrm{A}$ polymorphism is located in an IL-6 responsive HNF1 element and can alter the binding of a transactivation protein complex, resulting in greater luciferase reporter gene activity $[3,10]$. The other variant, $-148 \mathrm{C}>\mathrm{T}$, is almost in complete linkage disequilibrium with $-455 \mathrm{G}>\mathrm{A}$ in our population. The $-148 \mathrm{C}>\mathrm{T}$ polymorphism is located in a putative transforming growth factor- $\beta$ responsive element and is near to an IL-6 responsive element [27]. In a cohort of Italian Caucasians, plasma IL-6 and fibrinogen were elevated in subjects with impaired glucose tolerance, but not in those with impaired fasting glucose [4]. Thus, these variants may affect the cytokine and/or growth factor mediated transcription of $F G B$. Increased fibrinogen level may cause insulin secretion through endothelial dysfunction and vascular damage, leading to insulin resistance [18].

The independent association of AC-haplotype with 2-h glucose during OGTT, especially in men, is not surprising. Plasma fibrinogen level was correlated with 2-h glucose level, but not fasting glucose level. This is consistent with other reports, which show a positive relationship between fibrinogen level and the degree of glucose intolerance or severity of diabetes in men [16, 21]. The relationship of fibrinogen and diabetes in the Scottish Heart Health Study was significant only in men, but not women [17]. It was suggested that fibrinogen can indicate the degree of glucose intolerance, but not the development of diabetes in future [7]. In fact, the 2-h glucose level is a better predictor than fasting glucose level in the prediction of all-cause and cardiovascular mortality $[7,19]$. In this study, the AChaplotype was independently associated with higher 2$\mathrm{h}$ glucose in non-diabetic subjects, and such association was stronger than the fibrinogen level itself.

In conclusion, the $F G B$ haplotype $\mathrm{AC}$ was a major determinant of 2-h glucose levels in Hong Kong Chinese with normal glucose tolerance. This suggests that fibrinogen may play a role in the development of impaired glucose tolerance. Further studies are needed to confirm such association in a different setting or population with larger sample size. 


\section{Acknowledgements}

The Hong Kong Cardiovascular Risk Factor Prevalence Study Steering Committee consists of the following members: Professor ED Janus (Chairman), Professor CS Cockram, Dr R Fielding, Professor AJ Hedley, Dr P Ho, Professor KSL Lam, Professor TH Lam, Professor CP Lau, Ms Mona Lo, Dr SL Lo, Dr PL Ma, Professor JRC Maserei, Dr YT Tai, Professor B Tomlinson, Dr SP Wong, Professor JLF Woo, Dr. GN Thomas. The genetic analysis was supported by a grant from the University Department of Medicine Seeding Grant to RAP/PDF, the University of Hong Kong.

\section{Conflict of interest}

None.

\section{References}

[1] American Diabetes Association, Standards of Medical Care in Diabetes-2006, Diabetes Care 29 (2006), S4-42.

[2] J.C. Barrett, B. Fry, J. Maller and M.J. Daly, Haploview: analysis and visualization of LD and haplotype maps, Bioinformatics 21 (2005), 263-265.

[3] E.T. Brown and G.M. Fuller, Detection of a complex that associates with the Bbeta fibrinogen $\mathrm{G}-455$-A polymorphism, Blood 92 (1998), 3286-3293.

[4] M. Cardellini, F. Andreozzi, E. Laratta, M.A. Marini, R. Lauro, M.L. Hribal, F. Perticone and G. Sesti, Plasma interleukin6 levels are increased in subjects with impaired glucose tolerance but not in those with impaired fasting glucose in a cohort of Italian Caucasians, Diabetes Metab Res Rev 23 (2007), 141-145.

[5] J.V. Castell, M.J. Gomez-Lechon, M. David, T. Andus, T. Geiger, R. Trullenque, R. Fabra and P.C. Heinrich, Interleukin6 is the major regulator of acute phase protein synthesis in adult human hepatocytes, FEBS Lett 242 (1989), 237-239.

[6] A.V. Chobanian, G.L. Bakris, H.R. Black, W.C. Cushman, L.A. Green, J.L. Izzo, D.W. Jones, B.J. Materson, S. Oparil, J.T. Wright, E.J. Roccella and the National High Blood Pressure Education Program Coordinating Committee, Seventh report of the Joint National Committee on Prevention, Detection, Evaluation, and Treatment of High Blood Pressure, Hypertension 42 (2003), 1206-1252.

[7] DECODE Study Group, the European Diabetes Epidemiology Group, Glucose tolerance and cardiovascular mortality: comparison of fasting and 2-hour diagnostic criteria, Arch Intern Med 161 (2001), 397-405.

[8] E. Ernst and K.L. Resch, Fibrinogen as a cardiovascular risk factor: a meta-analysis and review of the literature, Ann Intern Med 118 (1993), 956-963.

[9] E.S. Ford, The metabolic syndrome and C-reactive protein, fibrinogen, and leukocyte count: findings from the Third National Health and Nutrition Examination Survey, Atherosclerosis 168 (2003), 351-358.
[10] S.E. Humphries, M. Cook, M. Dubowitz, Y. Stirling and T.W. Meade, Role of genetic variation at the fibrinogen locus in determination of plasma fibrinogen concentrations, Lancet $\mathbf{1}$ (1987), 1452-1455.

[11] G. Imperatore, G. Riccardi, C. Iovine, A.A. Rivellese and O. Vaccaro, Plasma fibrinogen: a new factor of the metabolic syndrome. A population-based study, Diabetes Care 21 (1998), 649-654.

[12] E.D. Janus, N.M. Wat, K.S. Lam, S.T. Siu, L.J. Liu and T.H. Lam; the Hong Kong Cardiovascular Risk Factor Steering Committee, The prevalence of diabetes, association with cardiovascular risk factors and implications of diagnostic criteria (ADA 1997 and WHO 1998) in a 1996 community-based population study in Hong Kong Chinese, Diabetes Med 17 (2000), 741-745.

[13] J.A. Kant, A.J. Fornace, Jr, D. Saxe, M.I. Simon, O.W. McBride and G.R. Crabtree, Evolution and organization of the fibrinogen locus on chromosome 4: gene duplication accompanied by transposition and inversion, Proc Natl Acad Sci USA 82 (1985), 2344-2348.

[14] W. Koenig, Fibrin(ogen) in cardiovascular disease: an update, Thromb Haemost 89 (2003), 601-609.

[15] T.H. Lam, L.J. Liu, E.D. Janus, C. Bourke and A.J. Hedley, The relationship between fibrinogen and other coronary heart disease risk factors in a Chinese population, Atherosclerosis 143 (1999), 405-413.

[16] T.H. Lam, L.J. Liu, E.D. Janus, K.S. Lam and A.J. Hedley; Hong Kong Cardiovascular Risk Factor Prevalence Study Steering Committee, Fibrinogen, other cardiovascular risk factors and diabetes mellitus in Hong Kong: a community with high prevalence of Type 2 diabetes mellitus and impaired glucose tolerance, Diabet Med 17 (2000), 798-806.

[17] A.J. Lee, G.D. Lowe, M. Woodward and H. Tunstall-Pedoe, Fibrinogen in relation to personal history of prevalent hypertension, diabetes, stroke, intermittent claudication, coronary heart disease, and family history: the Scottish Heart Health Study, Br Heart J 69 (1993), 338-342.

[18] S. Maumus, B. Marie, M. Vincent-Viry, G. Siest and S. Visvikis-Siest, Analysis of the effect of multiple genetic variants of cardiovascular disease risk on insulin concentration variability in healthy adults of the STANISLAS cohort. The role of FGB -455 G/A polymorphism, Atherosclerosis 191 (2007), 369-376.

[19] T. Nakagami; DECODA Study Group, Hyperglycaemia and mortality from all causes and from cardiovascular disease in five populations of Asian origin, Diabetologia 47 (2004), 385394.

[20] K.L. Ong, L.Y. Wong, Y.B. Man, R.Y. Leung, Y.Q. Song, K.S. Lam and B.M. Cheung, Haplotypes in the urotensin II gene and urotensin II receptor gene are associated with insulin resistance and impaired glucose tolerance, Peptides 27 (2006), 1659-1667.

[21] B.L. Rodriguez, J.D. Curb, C.M. Burchfiel, B. Huang, D.S. Sharp, G.Y. Lu, W. Fujimoto and K. Yano, Impaired glucose tolerance, diabetes, and cardiovascular disease risk factor profiles in the elderly. The Honolulu Heart Program,Diabetes Care 19 (1996), 587-590.

[22] S.N. Roy, G. Mukhopadhyay and C.M. Redman, Regulation of fibrinogen assembly. Transfection of Hep G2 cells with B beta cDNA specifically enhances synthesis of the three component chains of fibrinogen, J Biol Chem 265 (1990), 6389-6393.

[23] E.M. Scott, R.A. Ariens and P.J. Grant, Genetic and environmental determinants of fibrin structure and function: relevance 
to clinical disease, Arterioscler Thromb Vasc Biol 24 (2004), 1558-1566.

[24] G.D. Smith, R. Harbord, J. Milton, S. Ebrahim and J.A. Sterne, Does elevated plasma fibrinogen increase the risk of coronary heart disease? Evidence from a meta-analysis of genetic association studies, Arterioscler Thromb Vasc Biol 25 (2005), 2228-2233.

[25] M. Stephens and P. Donelly, A comparison of Bayesian methods for haplotype reconstruction from population genotype data, Am J Hum Genet 73 (2003), 1162-1169.

[26] M. Stephens, N. Smith and P. Donelly, A new statistical method for haplotype reconstruction from population data, $A m$ J Hum Genet 68 (2001), 978-989.
[27] A. Thomas, H. Lamlum, S. Humphries and F. Green, Linkage disequilibrium across the fibrinogen locus as shown by five genetic polymorphisms, G/A-455 (HaeIII), C/T-148 (HindIII/AluI), T/G+1689 (AvaII), and BclI (beta-fibrinogen) and TaqI (alpha-fibrinogen), and their detection by PCR, Hum Mutat 3 (1994), 79-81.

[28] L.Y. Wong, R.Y. Leung, K.L. Ong and B.M. Cheung, Plasma levels of fibrinogen and $\mathrm{C}$-reactive protein are related to interleukin-6 gene $-572 \mathrm{C}>\mathrm{G}$ polymorphism in subjects with and without hypertension, J Hum Hypertens 21 (2007), 875882 . 


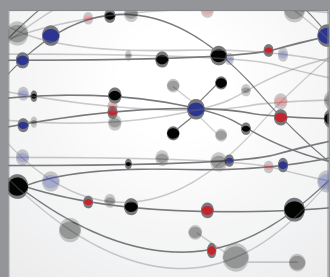

The Scientific World Journal
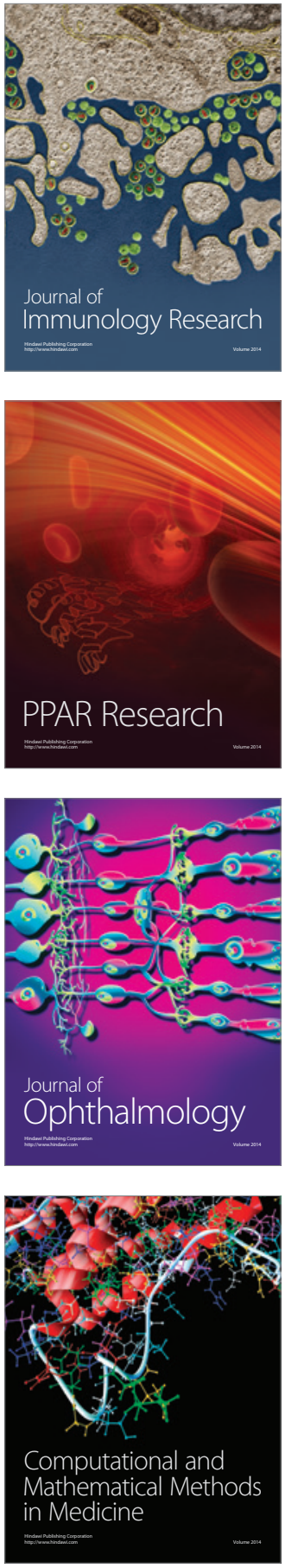

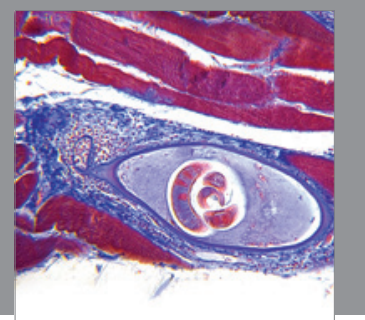

Gastroenterology

Research and Practice
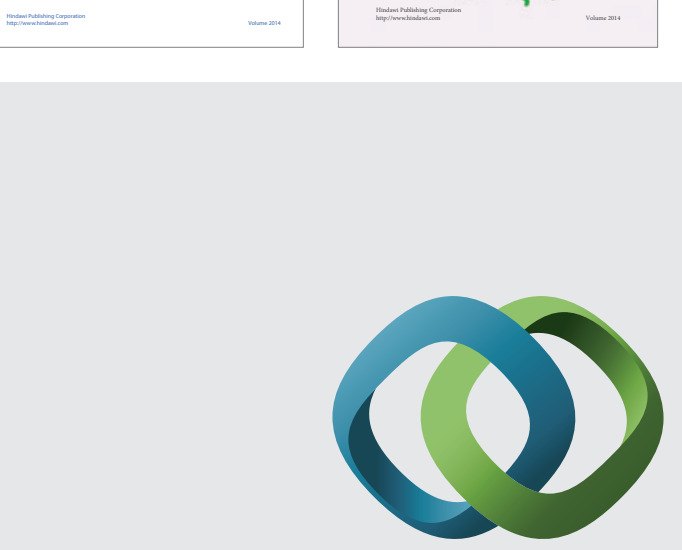

\section{Hindawi}

Submit your manuscripts at

http://www.hindawi.com
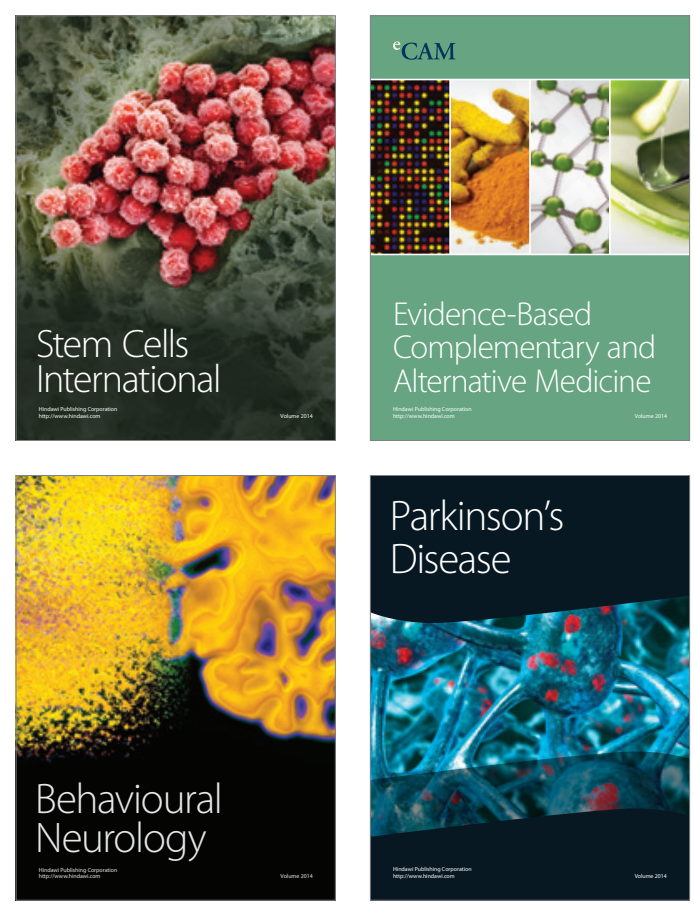

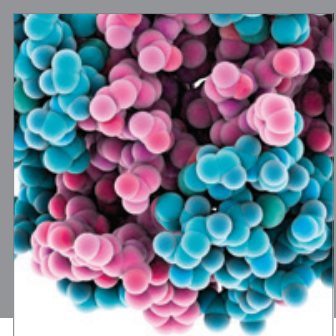

Journal of
Diabetes Research

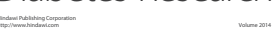

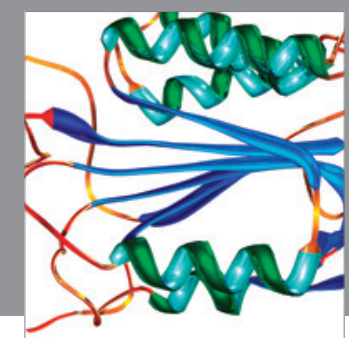

Disease Markers
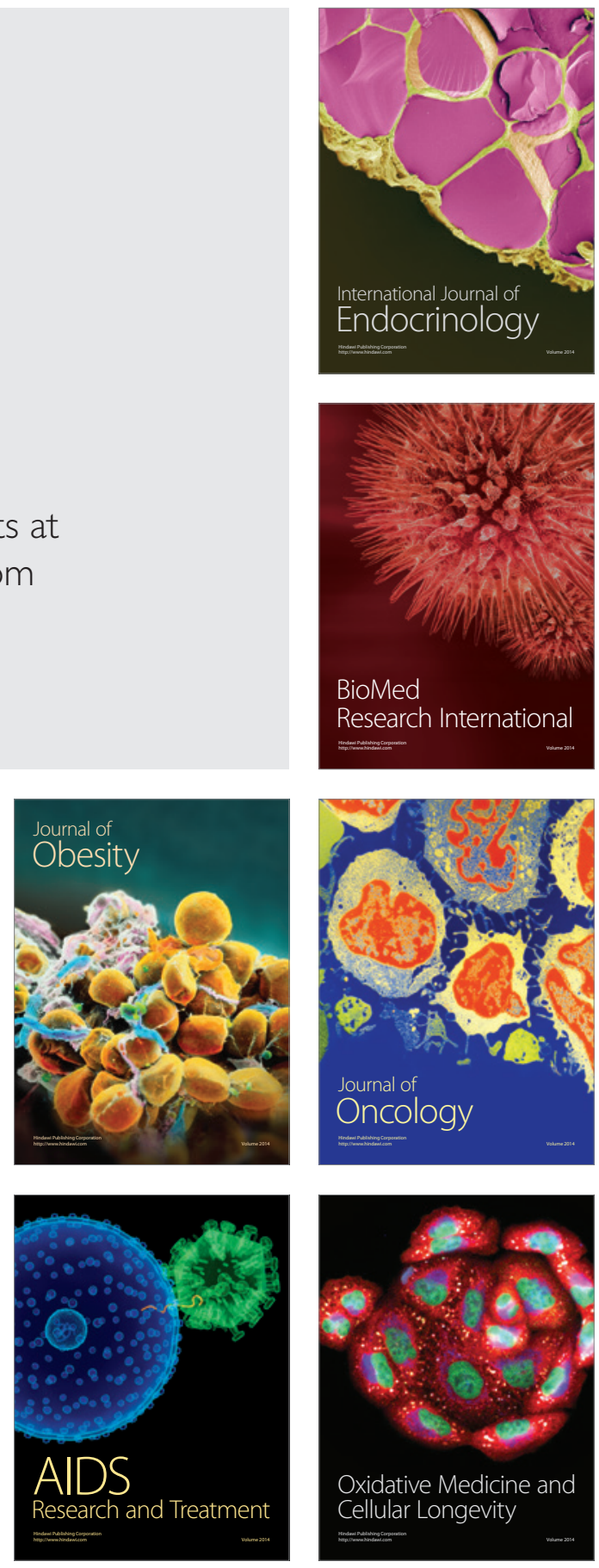